\title{
Cost-effectiveness of general practice care for low back pain: a systematic review
}

\author{
Chung-Wei Christine Lin - Marion Haas • \\ Chris G. Maher · Luciana A. C. Machado • \\ Maurits W. van Tulder
}

Received: 12 December 2010/ Accepted: 19 December 2010/Published online: 4 January 2011

(C) The Author(s) 2011. This article is published with open access at Springerlink.com

\begin{abstract}
Care from a general practitioner (GP) is one of the most frequently utilised healthcare services for people with low back pain and only a small proportion of those with low back pain who seek care from a GP are referred to other services. The aim of this systematic review was to evaluate the evidence on cost-effectiveness of GP care in non-specific low back pain. We searched clinical and economic electronic databases, and the reference list of relevant systematic reviews and included studies to June 2010. Economic evaluations conducted alongside randomised controlled trials with at least one GP care arm were eligible for inclusion. Two reviewers independently screened search results and extracted data. Eleven studies were included; the majority of which conducted a costeffectiveness or cost-utility analysis. Most studies investigated the cost-effectiveness of usual GP care. Adding
\end{abstract}

C.-W. C. Lin $(\bowtie) \cdot$ C. G. Maher

The George Institute for Global Health and Sydney Medical

School, The University of Sydney, PO Box M201,

Missenden Rd, Sydney, NSW 2050, Australia

e-mail: clin@george.org.au

\section{Haas}

Centre for Health Economics Research and Evaluation, The University of Technology, PO Box 123, Broadway, Sydney, NSW 2007, Australia

\section{A. C. Machado}

Departamento de Fisioterapia e Terapia Ocupacional, Universidade Federal de Minas Gerais, Av Antônio Carlos 6627, Pampulha, Belo Horizonte, MG 31270-901, Brazil

\section{W. van Tulder}

Department of Health Sciences, Faculty of Earth and Life Sciences, The EMGO Institute for Health and Care Research, VU University, de Boelelaan 1085, 1081 HV Amsterdam, The Netherlands advice, education and exercise, or exercise and behavioural counselling, to usual GP care was more cost-effective than usual GP care alone. Clinical rehabilitation and/or occupational intervention, and acupuncture were more costeffective than usual GP care. One study investigated the cost-effectiveness of guideline-based GP care, and found that adding exercise and/or spinal manipulation was more cost-effective than guideline-based GP care alone. In conclusion, GP care alone did not appear to be the most cost-effective treatment option for low back pain. GPs can improve the cost-effectiveness of their treatment by referring their patients for additional services, such as advice and exercise, or by providing the services themselves.

Keywords Low back pain - Cost-effectiveness analysis . Primary health care $\cdot$ Systematic review

\section{Introduction}

The direct (healthcare) and indirect (loss of productivity) costs of low back pain (LBP) have been estimated for several countries, in a number of studies, with each study reporting staggering costs [1]. For example, the conservative estimates for direct and indirect costs of LBP in United Kingdom were $£ 1,632$ and $£ 3,440$ million in 1998 [2]. These figures are likely to be higher today. In the United States, healthcare costs among people with spinal pain increased by $65 \%$ from 1997 to 2005 , more rapidly than the overall healthcare costs, and accounted for $9 \%$ of the total healthcare costs in 2005 [3]. Studies like these illustrate the need to efficiently use available healthcare budgets when managing LBP.

An economic evaluation takes into account the costs relative to the effects (outcomes) in a systematic 
comparison of two or more treatment alternatives $[4,5]$. It does not necessarily answer the question of what the cheapest intervention is. If an intervention is more effective than another intervention but associated with higher costs, the intervention may still be cost-effective if the ratio of costs and effects is acceptable. Hence, economic evaluations are designed to inform policy makers, clinicians and consumers about the relative efficiency (value-for-money) of treatment alternatives.

Care from a general practitioner (GP care) is one of the most frequently utilised healthcare services for LBP [2, 6]. The role of a GP working in primary care is to triage and provide first-line care to manage LBP. In managing LBP, GPs may be the sole provider of care or, in about $20 \%$ of patients [6, 7], GPs refer patients for additional healthcare services (e.g. physical therapy). The purpose of this systematic review was to critically appraise and summarise current evidence, retrieved from economic evaluations conducted alongside randomised controlled trials, on the cost-effectiveness of GP care compared to other treatment options for non-specific LBP.

\section{Methods}

We followed the method guidelines of the Cochrane Back Review Group [8, 9], Campbell and Cochrane Economic Methods Group (http://www.med.uea.ac.uk/research/ research_econ/cochrane/cochrane_home.htm), and the NHS Economic Evaluation Database Handbook [10]. Full economic evaluations (i.e. cost-minimisation, cost-effectiveness, cost-utility or cost-benefit analysis) undertaken from any perspective conducted alongside randomised controlled trials were included in this review. Studies which collected data on costs and/or utilisation but did not relate this information to a measure of benefit, or did not make inferences about the relative efficiency of the treatment alternatives, were excluded. Studies that recruited adults with non-specific LBP of any duration and included GP care in at least one intervention group were eligible for this review. We defined GP care as care provided by a general practitioner or doctor working in primary care. There was no restriction on the type of comparison group used. Studies that recruited multiple musculoskeletal conditions (e.g. neck or LBP), or investigated interventions implemented after spinal surgery were excluded. In addition, studies had to report costs and effects of the interventions, or an incremental cost-effectiveness ratio (ICER). There was no language restriction.

We used the Cochrane Back Review Group's search strategies to identify randomised controlled trials in LBP (http://www.cochrane.iwh.on.ca/pdfs/CBRG_searchstrat_ Sept08.pdf). Economic search terms (e.g. economics, costs and cost analysis) were developed from search strategies used by the NHS Economic Evaluation Database (NHS EED) (http://www.york.ac.uk/inst/crd/nhseedfaq02.htm). The following databases were searched from inception to 1 June 2010: Medline (via OvidSP), EMBASE (via OvidSP), CINAHL (via EBSCO), Cochrane Central Register of Controlled Trials (CENTRAL, via The Cochrane Library), PsychINFO (via OvidSP), PEDro, the American Economic Association's electronic bibliography (EconLit), NHS EED, and European Network of Health Economic Evaluation Databases (EURONHEED). The reference list of relevant systematic reviews and included studies were also searched. See Table 6 of Appendix for an example of a full search strategy.

Two reviewers independently screened first the titles, then abstracts (if available), and then full papers. For each included study, we used the criteria recommended by the Cochrane Back Review Group [8, 9] to assess the risk of bias of the trial design, where studies with a score of 6 or more out of a total of 11 would be considered as having a low risk of bias [11]. Studies were also rated using the Consensus on Health Economic Criteria (CHEC-list) [12] for the quality of the economic evaluation. Studies were included in the analysis regardless of their risk of bias or quality of economic evaluation. Data were extracted using a customised data extraction sheet which was piloted on a cost-effectiveness study [13] before use. Two reviewers independently performed rating and data extraction. Publications related to the included studies (e.g. published protocol or clinical outcomes paper, listed in Table 7 of Appendix) were used to assist these processes. Throughout the review, disagreement between the two reviewers were resolved first in discussion, and then by an independent third reviewer if necessary.

Data extracted from each study included: (a) the type and perspective of the economic evaluation, (b) characteristics of participants, (c) treatment comparators, (d) year, length, country and currency of the study, and (e) identification, measurement and valuation of costs and outcomes used in the economic evaluation, and (f) results of the study. Information on the relative cost-effectiveness of the interventions was used as the primary outcome in the review. This is usually reported as an incremental difference in costs relative to an incremental difference in effects, e.g. the ICER. Alternatively, where one treatment incurs lower costs and generates higher benefits compared to a treatment comparator, an ICER is not necessary and the treatment is said to be dominant.

For data analysis and presentation, studies were grouped first according to intervention, then by the type of economic evaluation conducted. In addition, regardless of the interventions investigated, studies reporting ICER using 
Fig. 1 Flow of studies

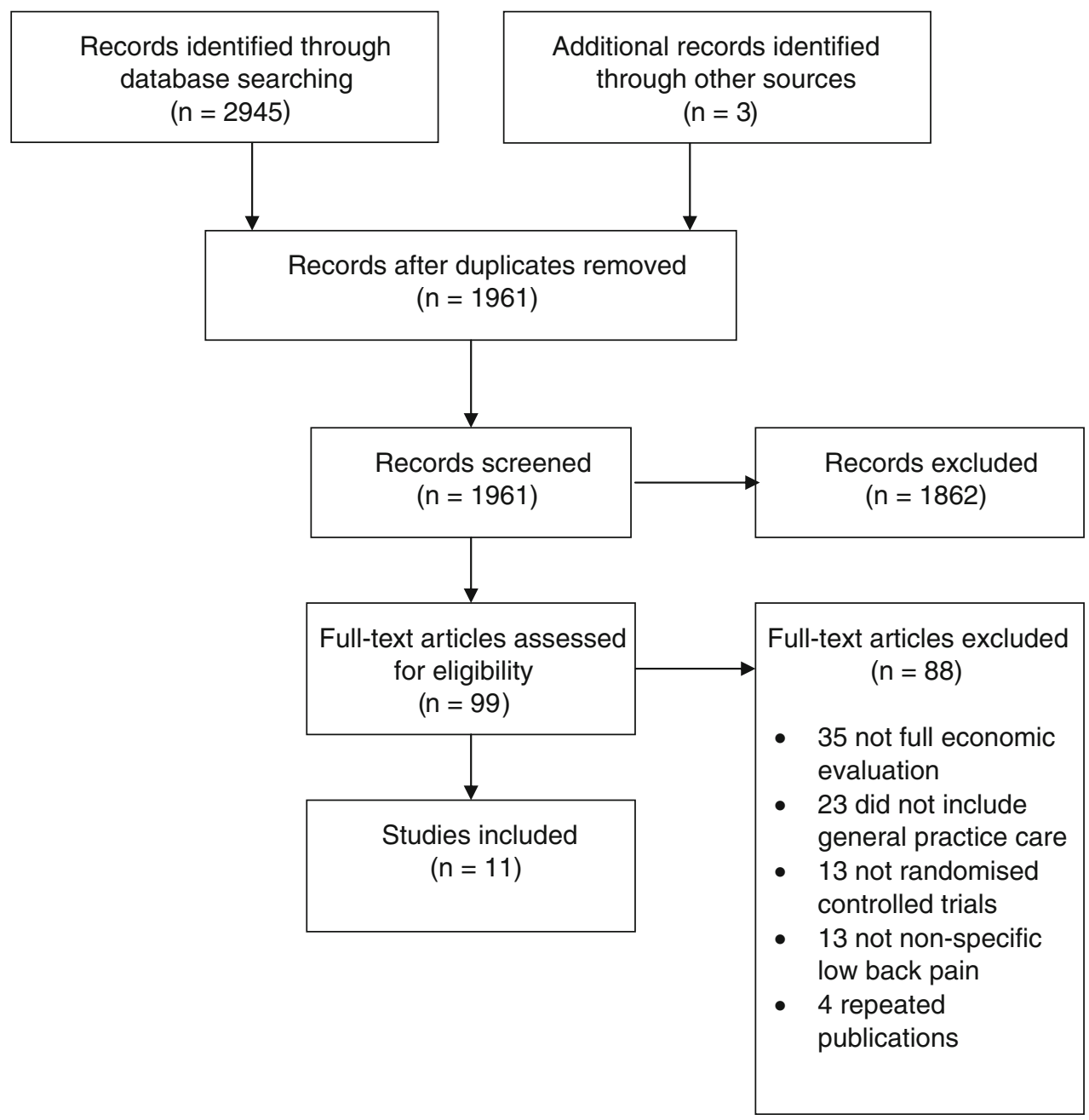

generic outcomes [e.g. cost per quality-adjusted life-years (QALYs) gained] from the same perspective were compared after adjusting for cost differences across countries and time. We used the cost-effectiveness threshold of the British National Institute for Health and Clinical Excellence (NICE; GBP20,000 to GBP30,000 per QALY gained) as an indicator of cost-effectiveness [14, 15]. That is, if a treatment has an ICER lower than the NICE threshold when compared to an alternative, the treatment is said to be relatively cost-effective.

\section{Results}

The search yielded 1,961 references and a total of 11 studies were included after screening (Fig. 1). Most full papers were excluded because they did not include a full economic evaluation or did not include GP care as at least one intervention group. All of the included studies were published in English. The number of participants ranged from 104 [16] to 1,334 [17]. Most studies included participants with sub-acute to chronic LBP. Table 1 has the characteristics of the included studies.

The majority of the studies conducted a cost-effectiveness and/or cost-utility analysis. There were also two costminimisation [18, 19] and two cost-benefit [20, 21] analyses. One study, which had one- and two-year results published in two separate papers [22, 23], did not clearly specify the type of economic evaluation conducted, but the type of outcomes reported suggested that it was a costeffectiveness analysis. Of the 11 included studies, all studies were conducted in Europe except for one conducted in the United States [18] and one in Canada [20].

We grouped studies into three groups: GP care alone versus other treatment (eight studies), GP care plus other treatment versus other treatment (one study), and GP care alone versus GP care plus additional treatment (five studies). Two studies [18, 24] had multiple comparisons and appeared in more than one treatment contrast. Most studies evaluated "usual GP care", i.e. they did not specify whether the treatments followed a protocol or guideline but provided care that included advice, exercises, rest and 
Table 1 Study characteristics

\begin{tabular}{|c|c|c|}
\hline $\begin{array}{l}\text { Study ID, type and } \\
\text { perspective }\end{array}$ & Study details & Groups \\
\hline \multicolumn{3}{|l|}{ Hollinghurst et al. [24] } \\
\hline Type: CEA/CUA & Participants randomised $(n): 435^{\mathrm{a}}$ & $\begin{array}{l}\text { Usual GP care } \pm \text { exercise and behavioural } \\
\text { counselling }\end{array}$ \\
\hline \multirow{3}{*}{$\begin{array}{l}\text { Perspective: healthcare } \\
\text { sector, patients, societal }\end{array}$} & Duration of LBP: chronic or recurrent & Massage \pm exercise and behavioural counselling \\
\hline & Length of follow-up: 12 months & $\begin{array}{l}\text { Alexander technique (6 lessons) } \pm \text { exercise and } \\
\text { behavioural counselling }\end{array}$ \\
\hline & Setting: United Kingdom 2002-2004 & \\
\hline \multicolumn{3}{|l|}{ Jellema et al. [25] } \\
\hline Type: CEA/CUA & Participants randomised $(n): 314$ & Usual GP care \\
\hline \multirow[t]{3}{*}{ Perspective: societal } & Duration of LBP: $<12$ weeks & $\begin{array}{l}\text { Minimal psychosocial intervention (delivered } \\
\text { by GP) }\end{array}$ \\
\hline & Length of follow-up: 12 months & \\
\hline & Setting: The Netherlands 2001-2003 & \\
\hline \multicolumn{3}{|l|}{ Johnson et al. [26] } \\
\hline Type: CEA/CUA & Participants randomised $(n): 234$ & Usual GP care \\
\hline \multirow[t]{3}{*}{ Perspective: not stated } & Duration of LBP: $>3$ months & $\begin{array}{l}\text { Exercise and education using a cognitive- } \\
\text { behavioural approach }\end{array}$ \\
\hline & Length of follow-up: 15 months & \\
\hline & Setting: United Kingdom 2002-2003 & \\
\hline \multicolumn{3}{|l|}{ Karjalainen et al. [22, 23] } \\
\hline \multirow{4}{*}{$\begin{array}{l}\text { Type and perspective: } \\
\text { not stated }\end{array}$} & Participants randomised $(n): 164$ & Usual GP care \\
\hline & Duration of LBP: $>4$ weeks but $<3$ months & Usual GP care plus advice, education and exercise \\
\hline & Length of follow-up: 24 months & $\begin{array}{l}\text { Usual GP care plus advice, education and exercise, } \\
\text { plus worksite visit }\end{array}$ \\
\hline & Setting: Finland 1998-2000 & \\
\hline \multicolumn{3}{|l|}{ Kominski et al. [18] } \\
\hline Type: CMA & Participants randomised $(n): 681$ & Usual GP care \\
\hline \multirow[t]{3}{*}{ Perspective: not stated } & Duration of LBP: mixed & Usual GP care plus physiotherapy \\
\hline & Length of follow-up: 18 months & Chiropractic care \\
\hline & Setting: United States 1995-1998 & Chiropractic care with physical modalities \\
\hline \multicolumn{3}{|l|}{ Kovacs et al. [16] } \\
\hline Type: CEA/CUA & Participants randomised $(n): 104$ & Usual GP care \\
\hline \multirow[t]{3}{*}{ Perspective: not stated } & Duration of LBP: $\geq 14$ days & Usual GP care plus neuroreflexotherapy \\
\hline & Length of follow-up: 12 months & \\
\hline & Setting: Spain, years not specified & \\
\hline \multicolumn{3}{|l|}{ Loisel et al. [20] } \\
\hline $\begin{array}{l}\text { Type: CEA/CUA and } \\
\text { CBA }\end{array}$ & Participants randomised $(n): 130$ & Usual GP care \\
\hline \multirow[t]{3}{*}{$\begin{array}{l}\text { Perspective: insurance } \\
\text { provider }\end{array}$} & $\begin{array}{l}\text { Duration of LBP: }>4 \text { weeks absent from work } \\
\text { due to LBP }\end{array}$ & $\begin{array}{l}\text { Clinical rehabilitation (back pain specialist, back } \\
\text { school } \pm \text { multidisciplinary rehabilitation) }\end{array}$ \\
\hline & Length of follow-up: mean 6.4 years & $\begin{array}{l}\text { Occupational intervention (occupation physician } \\
\text { and ergonomics intervention) }\end{array}$ \\
\hline & Setting: Canada 1991-1993 & $\begin{array}{l}\text { Clinical rehabilitation plus occupational } \\
\text { intervention }\end{array}$ \\
\hline \multicolumn{3}{|l|}{ Ratcliffe et al. [27] } \\
\hline Type: CEA/CUA & Participants randomised $(n): 241$ & Usual GP care \\
\hline $\begin{array}{l}\text { Perspective: healthcare } \\
\text { sector and societal }\end{array}$ & Duration of LBP: 4-52 weeks & Acupuncture \\
\hline
\end{tabular}


Table 1 continued

\begin{tabular}{|c|c|c|}
\hline $\begin{array}{l}\text { Study ID, type and } \\
\text { perspective }\end{array}$ & Study details & Groups \\
\hline & Length of follow-up: 24 months & \\
\hline & Setting: United Kingdom 1999-2001 & \\
\hline \multicolumn{3}{|l|}{ Seferlis et al. [19] } \\
\hline Type: CMA & Participants randomised $(n): 180$ & Usual GP care \\
\hline \multirow[t]{3}{*}{ Perspective: not stated } & Duration of LBP: $<2$ weeks on sick leave due to LBP & Manual therapy \\
\hline & Length of follow-up: 12 months & Exercise training \\
\hline & Setting: Sweden, years not specified & \\
\hline \multicolumn{3}{|l|}{ Skouen et al. [21] } \\
\hline Type: CBA & Participants randomised $(n): 211$ (195 completed follow up) & Usual GP care \\
\hline \multirow[t]{2}{*}{ Perspective: societal } & $\begin{array}{l}\text { Duration of LBP: sick leave for at least } 8 \text { weeks, or sick-listed } \\
\text { for at least } 2 \text { months a year for the last } 2 \text { years }\end{array}$ & Light multidisciplinary treatment \\
\hline & $\begin{array}{l}\text { Length of follow-up: } 24 \text { months after the end of treatment } \\
\text { Setting: Norway 1996-1997 }\end{array}$ & Extensive multidisciplinary treatment \\
\hline \multicolumn{3}{|l|}{ UK BEAM Trial Team [17] } \\
\hline Type: CEA/CUA & $\begin{array}{l}\text { Participants randomised }(n): 1,334(1,287 \text { included in } \\
\text { analysis) }\end{array}$ & Guideline-based GP care \\
\hline \multirow{3}{*}{$\begin{array}{l}\text { Perspective: healthcare } \\
\text { sector }\end{array}$} & Duration of LBP: at least 4 weeks & Guideline-based GP care plus exercise \\
\hline & Length of follow-up: 12 months & Guideline-based GP care plus spinal manipulation \\
\hline & Setting: United Kingdom 1999-2002 & $\begin{array}{l}\text { Guideline-based GP care plus combined treatment } \\
\text { (spinal manipulation followed by exercise) }\end{array}$ \\
\hline
\end{tabular}

$C B A$ cost-benefit analysis, $C E A$ cost-effectiveness analysis, $C M A$ cost-minimisation analysis, $C U A$ cost-utility analysis

${ }^{\text {a }}$ Data from a fourth group is not included in this review as no comparison was made between this group and GP care

prescription of medications with or without referrals to other services [16, 18, 19, 21]. A number of studies did not describe details of the GP care, except that it was the normal or usual care provided by a GP [20, 24-26] which may include referrals to other services [22, 23, 27]. The exception was the UK BEAM Trial [17], which provided training to GPs to deliver guideline care in the management of LBP ("guideline-based GP care").

Risk of bias of the trial design (Table 2)

Two studies did not use concealed allocation [16, 19] and two were unclear about the randomisation procedure [17, 19]. Assessor blinding was not achieved in most instances as studies used self-reports to measure outcome and participants could not be blinded due to the nature of the treatment. The only study that satisfied assessor blinding kept participants unaware that two treatments were being investigated [25]. Only 4 of the 11 studies were considered as having a low risk of bias [22-26].

Quality of the economic evaluation (Table 2)

Five studies collected costs appropriate to their chosen perspective $[17,20,24,25,27]$. One study undertook the
Table 2 Risk of bias rated using the criteria of the Cochrane Back Review Group [8,9] and methodological quality of the economic evaluation rated using the Consensus Health Economic Criteria (CHEC-list) [12]

\begin{tabular}{lll}
\hline & $\begin{array}{l}\text { Risk of bias } \\
\text { score }(/ 11)\end{array}$ & $\begin{array}{l}\text { CHEC-list } \\
(/ 19)^{\mathrm{a}}\end{array}$ \\
\hline Hollinghurst et al. [24] & 7 & $17(1)$ \\
Jellema et al. [25] & 9 & $18(1)$ \\
Johnson et al. [26] & 7 & $12(1)$ \\
Karjalainen et al. [22, 23] & 8 & $13(0)$ \\
Kominski et al. [18] & 5 & $11(4)$ \\
Kovacs et al. [16] & 4 & $15(1)$ \\
Loisel et al. [20] & 5 & $14(0)$ \\
Ratcliffe et al. [27] & 5 & $19(0)$ \\
Seferlis et al. [19] & 4 & $7(5)$ \\
Skouen et al. [21] & 5 & $14(1)$ \\
UK BEAM Trial Team [17] & 5 & $17(1)$ \\
\hline
\end{tabular}

${ }^{a}$ The number of items that were not applicable from the CHEC-list is in parentheses. For example, performing an incremental cost-effectiveness analysis (Item 13) was not applicable for cost-minimisation or cost-benefit analysis, and discounting (Item 14) was not applicable for studies with a follow-up of 1 year or less

economic evaluation from the societal perspective, but collected only costs associated with the study treatment and loss of productivity and not the costs of other treatments 
[21]. Five studies did not state the perspective adopted for the economic evaluation $[16,18,19,22,23,26]$. Most studies measured costs using diaries, questionnaires, or practice or insurance records, and valued costs appropriately using published sources. Where appropriate, most studies conducted an incremental cost-effectiveness analysis. The length of follow-up was at least 1 year for all of the studies. In three of the five studies in which the length of follow-up was more than 1 year, discounting was undertaken [21-23, 27]. Just over half the studies conducted a sensitivity analysis to account for uncertainties in their estimates of costs and effects [16, 17, 20, 24, 25, 27].

GP care alone versus other treatment (Table 3)

Eight studies investigated the cost-effectiveness of usual GP care alone versus other treatment. The costs of usual GP care alone were lower than other treatment if only costs to the healthcare sector were considered $[18,19,24,26$, 27]. However, usual GP care alone was generally associated with higher costs than other treatment if a broader perspective was adopted and the indirect costs associated with loss of productivity were included [19, 20, 24, 25]. In studies that conducted a cost-effectiveness or cost-utility analysis, there were no statistically significant betweengroup differences for most comparisons in the clinical outcomes used in the economic evaluation. The exceptions were the Alexander technique, which improved pain-free days (mean between-group difference $=13, \quad 95 \%$ $\mathrm{CI}=1-25)$ [24], and clinical rehabilitation and/or occupational intervention, which reduced days on full sickness benefits (mean between-group difference range from 190 to 292.7 days) [20]. These treatments also appeared costeffective compared to usual GP care alone. Massage was more costly and less effective than usual GP care alone, and therefore in this study GP care alone was the dominant treatment [24]. Ratcliffe et al. [27] found, when costs were considered from the societal perspective and using intention-to-treat analysis, that acupuncture was dominant compared with usual GP care alone.

Two studies conducted a cost-benefit analysis using sick-listed workers. Loisel et al. [20] showed that clinical rehabilitation and/or occupational intervention incurred lower healthcare and income replacement costs compared to usual GP care alone from the insurance provider's perspective. Skouen et al. [21] found similar results for light multidisciplinary treatment from the societal perspective, but interestingly only in male participants.

GP care plus other treatment versus other treatment

Only one study was included in this comparison [24]. This study found that usual GP care plus exercise and behavioural counselling was associated with lower costs than massage or the Alexander technique plus exercise and behavioural counselling from the perspectives of the healthcare sector and patient. There were no statistically significant between-group differences in disability, painfree days or QALY outcomes. However, the ICERs for both treatment alternatives were low, suggesting that these treatments were cost-effective compared to usual GP care plus exercise and behavioural counselling (ICER for massage plus exercise and behavioural counselling $=5,304$ per QALY gained, for the Alexander technique plus exercise and behavioural counselling $=5,332$ per QALY gained, in 2005 GBP from the healthcare sector's perspective).

\section{GP care alone versus GP care plus additional treatment}

Four studies compared usual GP care alone versus usual GP care plus additional treatment [16, 18, 22-24]. The costs of usual GP care alone were lower than usual GP care plus additional treatment if only costs to the healthcare sector were considered $[18,24]$. However, in studies that included the costs associated with loss of earnings or productivity, the total costs were lower when additional treatment was added to usual GP care [16, 22-24]. Three of the four studies included a cost-effectiveness or cost-utility analysis (Table 4). Adding exercise and behavioural counselling to usual GP care improved pain-free days (mean between-group difference $=11$ days, 95\% CI 1-23) and appeared relatively cost-effective from the healthcare sector's perspective [24]. Adding advice, education and exercise with or without worksite visit to usual GP care improved some outcomes (e.g. pain bothersomeness) and appeared cost-effective [22, 23]. One study found that adding neuroreflexology to GP care improved pain and disability, but not quality of life, outcomes [16]. However, there was no incremental cost-effectiveness analysis reported, and an ICER could not be estimated based on the data provided.

One study investigated the cost-effectiveness of guideline-based GP care, and found similar results to studies that investigated usual GP care [17]. From the healthcare sector's perspective, guideline-based GP care alone incurred lower costs compared to guideline-based GP care plus exercise and/or spinal manipulation. Adding spinal manipulation to guideline-based GP care was effective in managing sub-acute to chronic LBP (mean between-group difference $=0.04$ QALYs), and the ICER was low ( $£ 4,800$ in 2000 to 2001 GBP per QALY gained from the healthcare sector's perspective). In contrast, adding both spinal manipulation and exercise to guideline-based GP care did not statistically significantly increase the number of QALYs gained compared to 
Table 3 GP care alone versus other treatment

Study ID and perspective Incremental cost-effectiveness ratio (in cost per one unit of effect gained) or cost-benefit outcome

Cost-effectiveness/cost-utility analysis

Hollinghurst et al. [24]

Perspective: healthcare sector, patients, societal

Jellema et al. [25]

Perspective: societal

Compared to GP care alone from healthcare sector's perspective only, in 2005 GBP

Massage:

-Disability $(\mathrm{RMDQ})=448$

-Pain-free day $=26$

-QALY gained (EQ-5D) $=-34,473$ (less effective and more costly)

Alexander technique (6 lessons):

-Disability $(\mathrm{RMDQ})=113$

-Pain-free days = 13

$\bullet$ QALY gained $($ EQ-5D) $=5,899$

Minimal psychosocial intervention compared to GP care alone 2002 Euro:

-Disability $(\mathrm{RMDQ})=690$

- Recovery rate $(\%$ recovered $)=239$

$\bullet$ QALY gained (EQ-5D) $=47,348$

Johnson et al. [26]

Perspective: not stated, but collected

direct healthcare costs

Loisel et al. [20]

Perspective: insurance provider

Exercise and education using a cognitive-behavioural approach compared to GP care alone $=5,000$ in 2003-2004 GBP per QALY gained (EQ-5D)

Compared to GP care alone, in 1998 Canadian dollars per days on full sickness benefits:

-Clinical rehabilitation $=-67.6$

- Occupational intervention $=-88.4$

-Clinical rehabilitation plus occupational intervention $=-63.5$

Ratcliffe et al. [27]

Perspective: healthcare sector, societal

Acupuncture compared to usual GP care, in 2002-2003 GBP per QALY gained (EQ-5D):

-From healthcare sector's perspective $=4,241(95 \% \mathrm{CI}=191-28,026)$

-From societal perspective and with intention-to-treat analysis, acupuncture dominant

Cost-benefit analysis

Loisel et al. [20]

Perspective: insurance provider

Compared to GP care alone, in 1998 Canadian dollars:

-Clinical rehabilitation $=16,176$

- Occupational intervention $=16,827$

-Clinical rehabilitation plus occupational intervention $=18,585$

Skouen et al. [21]

Perspective: societal

Light multidisciplinary treatment in male patients compared to usual GP care alone $=7,240,900$ for the male participants $(n=21)$ over 24 months in 1998 Norwegian kroner

$G B P$ United Kingdom pounds, $R M D Q$ Roland Morris Disability Questionnaire, $Q A L Y$ quality-adjusted life-years

guideline-based GP care alone, but would only cost $£ 3,800$ per QALY gained. This shows that the most effective treatment may not be the most cost-effective treatment, as cost-effectiveness analysis considers costs relative to effects.

\section{Comparing cost-effectiveness across interventions} (Table 5)

Four studies collected costs from the healthcare sector's perspective using a common generic outcome (QALYs 
Table 4 Cost-effective/cost-utility analysis comparing usual GP care alone versus usual GP care plus additional treatment

\begin{tabular}{|c|c|}
\hline Study ID and perspective & Incremental cost-effectiveness ratio (in cost per one unit of effect gained) \\
\hline \multicolumn{2}{|l|}{ Hollinghurst et al. [24] } \\
\hline Perspective: healthcare sector, patients, societal & $\begin{array}{l}\text { Usual GP care plus exercise and behavioural counselling compared to } \\
\text { usual GP care alone from the healthcare sector's perspective only (in } \\
2005 \text { GBP): } \\
\text {-Disability (RMDQ) }=61 \\
\text {-Pain-free days }=9 \\
\text {-QALY gained (EQ-5D) }=2,847\end{array}$ \\
\hline \multicolumn{2}{|l|}{ Karjalainen et al. $[22,23]$} \\
\hline $\begin{array}{l}\text { Perspective: not stated, but collected direct } \\
\text { healthcare and indirect costs }\end{array}$ & $\begin{array}{l}\text { Not conducted, but usual GP care plus advice, education and exercise } \\
\text { with or without work site visit, incurred lower costs and was more } \\
\text { effective compared to usual GP care alone. }\end{array}$ \\
\hline \multicolumn{2}{|l|}{ Kovacs et al. [16] } \\
\hline $\begin{array}{l}\text { Perspective: not stated, but collected direct healthcare } \\
\text { and indirect costs }\end{array}$ & Not conducted \\
\hline
\end{tabular}

$G B P$ United Kingdom pounds, $R M D Q$ Roland Morris Disability Questionnaire, $Q A L Y$ quality-adjusted life-years

Table 5 Comparing the incremental cost-effectiveness ratio (ICER) in cost per quality-adjusted life-year gained from the healthcare sector's perspective

\begin{tabular}{|c|c|c|c|}
\hline Treatment & $\begin{array}{l}\text { Original } \\
\text { currency }\end{array}$ & $\begin{array}{l}\text { ICER in original } \\
\text { currency }\end{array}$ & $\begin{array}{l}\text { ICER in } 2005 \text { GBP } \\
\text { (rounded to the nearest pound) }\end{array}$ \\
\hline $\begin{array}{l}\text { Usual GP care plus exercise and } \\
\text { behavioural counselling [24] }\end{array}$ & 2005 GBP & 2,847 & 2,847 \\
\hline $\begin{array}{l}\text { Guideline-based GP care plus spinal } \\
\text { manipulation and exercise [17] }\end{array}$ & 2000-2001 GBP & 3,800 & 4,058 \\
\hline Acupuncture [27] & 2002-2003 GBP & 4,241 & 4,415 \\
\hline $\begin{array}{l}\text { Guideline-based GP care plus spinal } \\
\text { manipulation [17] }\end{array}$ & 2000-2001 GBP & 4,800 & 5,125 \\
\hline $\begin{array}{l}\text { Exercise and education using a cognitive- } \\
\text { behavioural approach [26] }\end{array}$ & 2003-2004 GBP & 5,000 & 5,136 \\
\hline $\begin{array}{l}\text { Massage plus exercise and behavioural } \\
\text { counselling [24] }\end{array}$ & 2005 GBP & 5,304 & 5,304 \\
\hline $\begin{array}{l}\text { Alexander technique plus exercise and } \\
\text { behavioural counselling [24] }\end{array}$ & 2005 GBP & 5,332 & 5,332 \\
\hline Alexander technique [24] & 2005 GBP & 5,899 & 5,899 \\
\hline $\begin{array}{l}\text { Guideline-based GP care plus exercise } \\
\text { [17] }\end{array}$ & 2000-2001 GBP & 8,300 & 8,863 \\
\hline Massage [24] & 2005 GBP & $-34,473$ & $\begin{array}{l}-34,473 \text { (more costly and } \\
\text { less effective) }\end{array}$ \\
\hline
\end{tabular}

Costs were converted to 2005 GBP using consumer price indices (http://www.statistics.gov.uk/downloads/theme_economy/CPI.pdf)

GBP United Kingdom pounds

gained) [17, 24, 26, 27]. Converting all costs to a common price year showed that all treatments, except for massage, had an ICER below the NICE threshold and appeared costeffective compared to GP care. The two most cost-effective treatment options were: (a) usual GP care combined with exercise and behavioural counselling, and (b) guidelinebased GP care combined with spinal manipulation and exercise.

\section{Discussion}

In this systematic review, we identified 11 relevant studies, most of which examined the cost-effectiveness of GP care in sub-acute or chronic LBP. When considering costs from the healthcare sector's perspective, GP care was associated with lower costs than other treatment alternatives, and this finding was consistent across healthcare systems. However, 
if the costs associated with loss of earnings or changes in productivity were included, GP care generally incurred higher costs than other treatments. Most treatments appeared relatively cost-effective compared to GP care. In particular, adding advice, education and exercise to usual GP care or providing clinical rehabilitation and/or occupational intervention or acupuncture were dominant treatment alternatives (i.e. they incurred lower costs and generated more benefits) compared to usual GP care alone. Adding exercise and behavioural counselling to usual GP care, or spinal manipulation to guideline-based GP care, and using the Alexander technique were more effective and may also be more cost-effective, as indicated by ICERs below the NICE threshold of GBP20,000 to GBP30,000.

These findings have important clinical and research implications. They suggest that GP care alone may not be the most cost-effective treatment for LBP, yet currently only around one-fifth of patients with LBP presenting to GPs are referred to another healthcare service [6, 7]. In addition, evidence-based management of LBP is typically based on effectiveness outcomes from trials. Our review findings suggest that evidence of cost-effectiveness should also be considered by clinicians and researchers when making recommendations regarding the management of LBP. Compared to GP care, when alternative treatments incur lower costs and are more effective (e.g. acupuncture), or incur higher costs and are less effective (e.g. massage), the choice for the most efficient treatment option is straight forward. In the absence of a clear difference in treatment effects, the results of economic evaluations can provide information on the relative efficiency of treatment alternatives. Because both the incremental costs and the effects are taken into account in an economic evaluation, a treatment may be relatively cost-effective compared to an alternative treatment even if the difference in clinical effectiveness is small. Hence, future studies should consider including an economic evaluation in order to provide comprehensive information on both effectiveness and efficiency of treatments in managing LBP [28]. Conducting economic evaluations has recently been regarded as a research priority in musculoskeletal conditions such as LBP [29].

In all but one study the GP intervention was the usual care provided by a GP. In contrast, the additional or alternative services, such as exercise and advice, were usually delivered according to a defined protocol that represented best practice. Surveys of usual GP care reveal low compliance with care recommended in guidelines [6, 7]. Hence, comparing usual GP care to a best practice alternative potentially under-estimates GP care and needs to be borne in mind when interpreting the results of this review. A number of trials found that referring a patient for additional services was more cost-effective than usual GP care alone. It is acknowledged that some of the additional services, e.g. advice/education and exercise prescription, could be provided by some GPs who manage LBP. Our pragmatic interpretation of the results of our review is that GPs aiming to provide cost-effective care should ensure that their patients receive these additional services, either by referral (as occurred in the original trial) or by providing the services themselves.

Most economic evaluations identified by this review were conducted as cost-effectiveness or cost-utility analyses. While a cost-effective analysis provides data that may be more meaningful to clinicians (e.g. adding exercise and behavioural counselling to usual GP care would cost $£ 61$ in 2005 GBP per one point gained on the Roland Morris Disability Questionnaire) [24], a cost-utility analysis provides information using a generic outcome (most commonly cost per QALY gained) that can be compared across interventions and health conditions [4] and assist policy makers in making decisions on reimbursing existing or new treatments. In our review, we used the NICE threshold to assess the cost-effectiveness of LBP treatments. The NICE threshold has not changed since 1999. While controversies exist on the use of such a threshold and on whether the threshold should be altered [14, 15, 30, 31], most treatments for LBP have ICERs well below the current threshold. It needs to be highlighted, however, that the findings of this review are based on single studies as the heterogeneity of the included studies prevented the pooling of data. Only 4 of the 11 included studies had a low risk of bias. In addition, the findings may be limited to countries with similar healthcare systems, and, for cost-utility analysis, to populations where similar utility weights can be expected.

In our review we identified two cost-minimisation studies [18, 19]. Cost-minimisation analysis is used when treatment alternatives achieve the same outcomes in effectiveness, but the appropriateness of its use is controversial because the lack of a demonstrative difference between two treatments may be due to insufficient power rather than an absence of effects [32]. Hence, it may be only appropriate to conduct a cost-minimisation analysis where an equivalence trial has been conducted [33] or when the confidence intervals of the between-group treatment effects are narrow enough to rule out potential treatment effects. For example, Kominski et al. [18] conducted a cost-minimisation analysis based on the results of a randomised controlled trial, which showed narrow between-group differences in treatment outcomes [34]. Some authors do not recommend cost-minimisation analysis as they argue that economic evaluations should be used to provide estimates of the incremental difference in costs relative to the incremental difference in effects (i.e. the incremental cost-effectiveness) rather than hypothesis testing [32]. 
Six similar reviews have been published previously [3540]. Results of these reviews were either inconclusive [35$37,39]$, failed to demonstrate economic benefits of interventions for LBP [38], or focused on the qualitative description of the economic design [40]. In contrast to these reviews, and due to an increasing number of available studies, we were able to selectively include randomised controlled trials which conducted a full economic evaluation. Compared to a previous review [40], there is a trend showing that the quality of economic evaluation has improved, particularly in the identification, measurement and valuation of cost, and conducting an incremental costeffectiveness analysis and sensitivity analysis. It is important to note that the strength of this review is not that it gives an ultimate answer to the question which intervention is most cost-effective, but in the summary of all available economic evaluations for GP care in LBP.

The aim of our review was to investigate the cost-effectiveness of GP care in managing LBP. Therefore, while studies normally report a range of condition-specific clinical outcomes, we extracted only the outcomes used in the economic evaluation. For the treatments that were dominant compared to GP care or may be cost-effective when added to GP care, there is some evidence of small effects in the clinical outcomes not used in the economic evaluation [22, $23,41-44]$. There is also some evidence of small or shortterm effectiveness on condition-specific outcomes for acupuncture [45] and exercise [46] in systematic reviews of treatment effectiveness, but not so for spinal manipulation when provided in addition to GP care [47, 48].

Findings of this systematic review suggest that although GP care alone was often associated with lower treatment costs from the healthcare sector's perspective, it may not provide a cost saving for society if the costs associated with loss of earnings or productivity are taken into account. When considering costs relative to effects, GP care alone may not be cost-effective in managing sub-acute or chronic LBP. Adding advice, education and exercise to usual GP care, clinical intervention and/or occupational rehabilitation, and acupuncture appeared to dominate over usual GP care. Adding exercise and behavioural counselling to usual GP care, adding exercise and/or spinal manipulation to guideline-based GP care, and using the Alexander technique also appeared cost-effective. The cost-effectiveness of GP care can be improved by referring patients to receive additional services, such as advice and exercise, or by the GPs providing the additional services themselves.

Acknowledgments CL and CM are funded by the National Health and Medical Research Council, Australia. LM is funded by Fundação de Amparo à Pesquisa do Estado de Minas Gerais (FAPEMIG), Brazil.

Conflict of interest None.
Open Access This article is distributed under the terms of the Creative Commons Attribution Noncommercial License which permits any noncommercial use, distribution, and reproduction in any medium, provided the original author(s) and source are credited.

\section{Appendix}

See Tables 6 and 7.

Table 6 Search strategy for Medline (via OvidSP)

Part A: Generic search for randomized controlled trials and controlled clinical trials

1 Clinical Trial .pt.

2 randomized.ab,ti.

3 placebo.ab,ti.

4 dt.fs.

5 randomly.ab,ti.

6 trial.ab,ti.

7 groups.ab,ti.

8 or/1-7

9 Animals/

10 Humans/

119 not (9 and 10)

128 not 11

Part B: Specific search for low back problems

13 dorsalgia.ti,ab.

14 exp Back Pain/

15 backache.ti,ab.

16 exp Low Back Pain/

17 (lumbar adj pain).ti,ab.

18 lumbago.ti,ab.

19 or/13-18

Part C: Specific search for economic evaluation

20 economics/

21 exp "costs and cost analysis"/

22 economics, dental/

23 exp "economics, hospital"/

24 economics, medical/

25 economics, nursing/

26 economics, pharmaceutical/

27 (economic\$ or cost or costs or costly or costing or price or prices or pricing or pharmacoeconomic\$).ti,ab.

28 (expenditure\$ not energy).ti,ab.

29 (value adj1 money).ti,ab.

30 budget\$.ti,ab.

31 or/20-30

32 ((energy or oxygen) adj cost).ti,ab.

33 (metabolic adj cost).ti,ab.

34 ((energy or oxygen) adj expenditure).ti,ab.

35 or/32-34 
Table 6 continued

3631 not 35

Part D: Combine

3712 AND 19 AND 36

Table 7 Publications related to the included studies used during the review process

\begin{tabular}{ll}
\hline Included studies & Related publications \\
\hline Hollinghurst et al. [24] & Little et al. [41] \\
Jellema et al. [25] & Jellema et al. [49] \\
Johnson et al. [26] & Nil \\
Karjalainen et al. [22, 23] & Nil \\
Kominski et al. [18] & Hurwitz et al. [34] \\
Kovacs et al. [16] & Nil \\
Loisel et al. [20] & Loisel et al. [42] \\
Ratcliffe et al. [27] & Thomas et al. [43] \\
Seferlis et al. [19] & Seferlis et al. [50] \\
Skouen et al. [21] & Haldorsen et al. [51] \\
UK BEAM Trial Team [17] & UK BEAM Trial Team [49], \\
& Brealey et al. [52] \\
\hline
\end{tabular}

\section{References}

1. Dagenais S, Caro J, Haldeman S (2008) A systematic review of low back pain cost of illness studies in the United States and internationally. Spine J 8(1):8-20

2. Maniadakis N, Gray A (2000) The economic burden of back pain in the UK. Pain 84(1):95-103

3. Martin BI, Deyo RA, Mirza SK, Turner JA, Comstock BA, Hollingworth W, Sullivan SD (2008) Expenditures and health status among adults with back and neck problems. JAMA 299(6):656-664

4. Drummond MF, Sculpher MJ, Torrance GW, O'Brien BJ, Stoddart GL (2005) Methods for the economic evaluation of health care programmes, 3rd edn. Oxford University Press, Oxford

5. Haas M (2003) Economic evaluation: a useful research method. Aust J Physiother 49(2):85-86

6. Williams CM, Maher CG, Hancock MJ, McAuley JH, McLachlan AJ, Britt H, Fahridin S, Harrison C, Latimer J (2010) Low back pain and best practice care. A survey of general practice physicians. Arch Int Med 170(3):271-277

7. Jackson JL, Browning R (2005) Impact of national low back pain guidelines on clinical practice. South Med J 98(2):139-143

8. van Tulder M, Furlan A, Bombardier C, Bouter L, Editorial Board of the Cochrane Collaboration Back Review Group (2003) Updated method guidelines for systematic reviews in the Cochrane Collaboration Back Review Group. Spine 28(12):12901299

9. Furlan AD, Pennick V, Bombardier C, van Tulder M, Editorial Board Cochrane Back Review Group (2009) 2009 updated method guidelines for systematic reviews in the Cochrane Back Review Group. Spine 34(18):1929-1941
10. Craig D, Rice S (2007) Crd report 6: NHS economic evaluation database handbook, 3rd edn. Centre for Reviews and Dissemination, University of York, York

11. van Tulder M, Suttorp M, Morton S, Bouter L, Shekelle P (2009) Empirical evidence of an association between internal validity and effect size in randomized controlled trials of low-back pain. Spine 34(16):1685-1692

12. Evers S, Goossens M, de Vet H, van Tulder M, Ament A (2005) Criteria list for assessment of methodological quality of economic evaluations: consensus on health economic criteria. Int $\mathrm{J}$ Technol Assess Health Care 21(2):240-245

13. Manca A, Epstein DM, Torgerson DJ, Klaber Moffett JA, Coulton S, Farrin AJ, Hahn S, Jackson DA, Richmond SJ (2006) Randomized trial of a brief physiotherapy intervention compared with usual physiotherapy for neck pain patients: cost-effectiveness analysis. Int J Technol Assess Health Care 22(1):67-75

14. Appleby J, Devlin N, Parkin D (2007) Nice's cost effectiveness threshold. BMJ 335(7616):358-359

15. Towse A (2009) Should nice's threshold range for cost per QALY be raised? Yes. BMJ 338:b181. doi:10.1136/bmj.b181

16. Kovacs FM, Llobera J, Abraira V, Lazaro P, Pozo F, Kleinbaum D, Group KAP (2002) Effectiveness and cost-effectiveness analysis of neuroreflexotherapy for subacute and chronic low back pain in routine general practice: a cluster randomized, controlled trial. Spine 27(11):1149-1159

17. UK BEAM Trial Team (2004) United Kingdom back pain exercise and manipulation (UK beam) randomised trial: cost effectiveness of physical treatments for back pain in primary care. BMJ 329(7479):1381-1385

18. Kominski GF, Heslin KC, Morgenstern H, Hurwitz EL, Harber PI (2005) Economic evaluation of four treatments for low-back pain: results from a randomized controlled trial. Med Care 43(5): $428-435$

19. Seferlis T, Lindholm L, Nemeth G (2000) Cost-minimisation analysis of three conservative treatment programmes in 180 patients sick-listed for acute low-back pain. Scand J Prim Health Care 18(1):53-57

20. Loisel P, Lemaire J, Poitras S, Durand MJ, Champagne F, Stock S, Diallo B, Tremblay C (2002) Cost-benefit and cost-effectiveness analysis of a disability prevention model for back pain management: a six year follow up study. Occup Environ Med 59(12):807-815

21. Skouen JS, Grasdal AL, Haldorsen EMH, Ursin H (2002) Relative cost-effectiveness of extensive and light multidisciplinary treatment programs versus treatment as usual for patients with chronic low back pain on long-term sick leave: randomized controlled study. Spine 27(9):901-909

22. Karjalainen K, Malmivaara A, Mutanen P, Roine R, Hurri H, Pohjolainen T (2004) Mini-intervention for subacute low back pain: two-year follow-up and modifiers of effectiveness. Spine 29(10): 1069-1076

23. Karjalainen K, Malmivaara A, Pohjolainen T, Hurri H, Mutanen P, Rissanen P, Pahkajarvi H, Levon H, Karpoff H, Roine R (2003) Mini-intervention for subacute low back pain: a randomized controlled trial. Spine 28(6):533-540

24. Hollinghurst S, Sharp D, Ballard K, Barnett J, Beattie A, Evans M, Lewith G, Middleton K, Oxford F, Webley F, Little P (2008) Randomised controlled trial of alexander technique lessons, exercise, and massage (ateam) for chronic and recurrent back pain: economic evaluation. BMJ 337:a2656

25. Jellema $P$, van der Roer N, van der Windt DAWM, van Tulder MW, van der Horst HE, Stalman WAB, Bouter LM (2007) Low back pain in general practice: cost-effectiveness of a minimal psychosocial intervention versus usual care. Eur Spine J 16(11):1812-1821 
26. Johnson RE, Jones GT, Wiles NJ, Chaddock C, Potter RG, Roberts C, Symmons DPM, Watson PJ, Torgerson DJ, Macfarlane GJ (2007) Active exercise, education, and cognitive behavioral therapy for persistent disabling low back pain: a randomized controlled trial. Spine 32(15):1578-1585

27. Ratcliffe J, Thomas KJ, MacPherson H, Brazier J (2006) A randomised controlled trial of acupuncture care for persistent low back pain: cost effectiveness analysis. BMJ 333(7569):626

28. Dowie J (2004) Why cost-effectiveness should trump (clinical) effectiveness: the ethical economics of the south west quadrant. Health Econ 13(5):453-459

29. Foster NE, Dziedzic KS, van der Windt DA, Fritz JM, Hay EM (2009) Research priorities for non-pharmacological therapies for common musculoskeletal problems: nationally and internationally agreed recommendations. BMC Musculoskelet Disorder 10:3

30. Pearson SD, Rawlins MD (2005) Quality, innovation, and value for money: NICE and the British National Health Service. JAMA 294(20):2618-2622

31. Raftery J (2009) Should NICE's threshold range for cost per QALY be raised? No. BMJ 338:b185. doi:10.1136/bmj.b185

32. Briggs AH, O'Brien BJ (2001) The death of cost-minimization analysis? Health Econ 10(2):179-184

33. Piaggio G, Elbourne DR, Altman DG, Pocock SJ, Evans SJW (2006) Reporting of noninferiority and equivalence randomised trials: an extension of the consort statement. JAMA 295:11521160

34. Hurwitz EL, Morgenstern H, Harber P, Kominski GF, Belin TR, Yu F, Adams AH (2002) A randomized trial of medical care with and without physical therapy and chiropractic care with and without physical modalities for patients with low back pain: 6month follow-up outcomes from the UCLA low back pain study. Spine 27(20):2193-2204

35. Baldwin ML, Côté P, Frank JW, Johnson WG (2001) Costeffectiveness studies of medical and chiropractic care for occupational low back pain. A critical review of the literature. Spine J 1(2): 138-147

36. Dagenais S, Roffey DM, Wai EK, Haldeman S, Caro J (2009) Can cost utility evaluations inform decision making about interventions for low back pain? Spine J 9(11):944-957

37. Goossens MEJB, Evers SMAA (1997) Economic evaluation of back pain interventions. J Occup Rehabil 7(1):15-32

38. Maetzel A, Li L (2002) The economic burden of low back pain: a review of studies published between 1996 and 2001. Best Pract Res Clin Rheumatol 16(1):23-30

39. Thomsen AB, Sørensen J, Sjøgren P, Eriksen J (2001) Economic evaluation of multidisciplinary pain management in chronic pain patients: a qualitative systematic review. J Pain Symptom Manage 22(2):688-698

40. van der Roer N, Goossens ME, Evers SM, van Tulder MW (2005) What is the most cost-effective treatment for patients with low back pain? A systematic review. Best Pract Res Clin Rheumatol 19(4):671-684

41. Little P, Lewith G, Webley F, Evans M, Beattie A, Middleton K, Barnett J, Ballard K, Oxford F, Smith P, Yardley L, Hollinghurst S, Sharp D (2008) Randomised controlled trial of alexander technique lessons, exercise, and massage (ateam) for chronic and recurrent back pain. BMJ 337:a884

42. Loisel P, Abenhaim L, Durand P, Esdaile JM, Suissa S, Gosselin L, Simard R, Turcotte J, Lemaire J (1997) A population-based, randomized clinical trial on back pain management. Spine 22(24):2911-2918

43. Thomas KJ, MacPherson H, Ratcliffe J, Thorpe L, Brazier J, Campbell M, Fitter M, Roman M, Walters S, Nicholl JP (2005) Longer term clinical and economic benefits of offering acupuncture care to patients with chronic low back pain. Health Technol Assess 9(32):iii-iv, ix-x, 1-109

44. UK BEAM Trial Team (2004) United Kingdom back pain exercise and manipulation (UK beam) randomised trial: effectiveness of physical treatments for back pain in primary care. BMJ 329(7479):1377

45. Furlan AD, van Tulder MW, Cherkin D, Tsukayama H, Lao L, Koes BW, Berman BM (2005) Acupuncture and dry-needling for low back pain. Cochrane Database Syst Rev Issue 1:CD001351. doi:001310.001002/14651858.CD14001351.pub14651852

46. Hayden J, van Tulder MW, Malmivaara A, Koes BW (2005) Exercise therapy for treatment of non-specific low back pain. Cochrane Database Syst Rev Issue 3:CD000335. doi:000310. 001002/14651858.CD14000335.pub14651852

47. Assendelft WJJ, Morton SC, Yu EI, Suttorp MJ, Shekelle PG (2004) Spinal manipulative therapy for low-back pain. Cochrane Database Syst Rev Issue 1:CD000447. doi:000410.001002/ 14651858.CD14000447.pub14651852

48. Hancock MJ, Maher CG, Latimer J, McLachlan AJ, Cooper CW, Day RO, Spindler MF, McAuley JH (2007) Assessment of diclofenac or spinal manipulative therapy, or both, in addition to recommended first-line treatment for acute low back pain: a randomised controlled trial. Lancet 307(9599):1638-1643

49. Jellema P, van der Windt DA, van der Horst HE, Twisk JW, Stalman WA, Bouter LM (2005) Should treatment of (sub)acute low back pain be aimed at psychosocial prognostic factors? Cluster randomised clinical trial in general practice. BMJ 331:84

50. Seferlis T, Németh G, Carlsson AM, Gillström P (1998) Conservative treatment in patients sick-listed for acute low-back pain: a prospective randomised study with 12 months' follow-up. Eur Spine J 7:461-470

51. Haldorsen EM, Grasdal AL, Skouen JS, Risa AE, Kronholm K, Ursin H (2002) Is there a right treatment for a particular patient group? Comparison of ordinary treatment, light multidisciplinary treatment, and extensive multidisciplinary treatment for longterm sick-listed employees with musculoskeletal pain. Pain 95:49-63

52. Brealey S, Burton K, Coulton S, Farrin A, Garratt A, Harvey E, Letley L, Martin J, Klaber MJ, Russell I, Torgerson D, Underwood M, Vickers M, Whyte K, Williams M, UK Back Pain Exercise, Manipulation (UK BEAM) Trial Team (2003) UK Back Pain Exercise and Manipulation (UK BEAM) trial-national randomised trial of physical treatments for back pain in primary care: objectives, design and interventions [ISRCTN32683578]. BMC Health Services Res 3:16 